\title{
Collaborative organizational forms: on communities, crowds, and new hybrids
}

Vegard Kolbjørnsrude

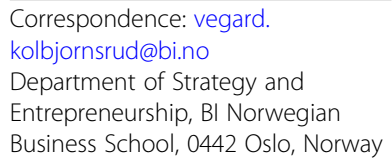

\begin{abstract}
In this article, I examine collaborative organizational forms in terms of their institutional properties and the mechanisms by which they solve the universal problems of organizing. Based on three ideal forms-markets, hierarchies, and communities - I propose a framework for analyzing and mapping organizational forms. The framework expands our understanding of the ideal forms and derives a set of analytically distinct hybrids at the intersection of the ideal types. The framework also specifies the main conditions that drive organizations to change form and move toward another hybrid or ideal form. The theoretical review of collaborative organizational forms is illustrated and informed by three empirical cases of new forms within the domains of drug discovery, software development, as well as professional services. Further, I discuss plural forms and the role of hierarchy in collaborative forms. Finally, I outline implications for research and practice in terms of comparative analysis of organizational forms, the role of crowds, as well as the interplay between new technologies and new organizational forms.
\end{abstract}

Keywords: Collaborative organizational forms, Community, Market, Hierarchy, Hybrid, Crowd, Plural forms

New collaborative organizational forms such as collaborative communities, crowd contests, as well as holacracy and other forms of self-governance are emerging (Adler et al. 2008; Bernstein et al. 2016; Lakhani et al. 2013). Powered by digital technologies, they are transforming major industries and societal sectors such as software, transportation, hotels and accommodation, scientific discovery, healthcare, military operations, and are even changing how we source and organize knowledge and labor (Alberts et al. 1999; Autor 2001; Collins et al. 2003; Garud et al. 2008; Lerner and Tirole 2002).

The literature refers to these by a plethora of overlapping terms and concepts (Child and McGrath 2001; Schreyögg and Sydow 2010) for collaborative organizational forms such as the I-form (Miles et al. 2009), the virtual organization (Handy 1995; Mowshowitz 1994), the C-form (Seidel and Stewart 2011), bazaar governance (Demil and Lecocq 2006), the collaborative community (Heckscher and Adler 2006; Snow et al. 2011), the meta-organization (Gulati et al. 2012), and actor-oriented organizations (Fjeldstad et al. 2012). Echoing calls for research and theory on adaptive, self-organizing, and innovative organizations (e.g., Child and McGrath 2001; Daft and Lewin 1993; Schreyögg and Sydow 2010), there is a need for a systematic way for scholars and practitioners to discuss, analyze, and design collaborative organizational forms as well as to understand the dynamism and heterogeneity contemporary organizations demonstrate. Further, organizations

(c) The Author(s). 2018 Open Access This article is distributed under the terms of the Creative Commons Attribution 4.0 International License (http://creativecommons.org/licenses/by/4.0/), which permits unrestricted use, distribution, and reproduction in any medium, provided you give appropriate credit to the original author(s) and the source, provide a link to the Creative Commons license, and indicate if changes were made. 
mix and match mechanisms from a variety of forms into new, rapidly evolving hybridsof which some are radically different from the conventional market-hierarchy hybrids known from the classic economic organization literature (e.g., Shah 2006). We need a better understanding of the distinctive design properties of collaborative organizational forms including new collaborative hybrids. In particular, we need a coherent framework to describe, analyze, and conceptualize collaborative organizational forms and how they relate to conventional designs.

In this study, I examine collaborative organizational forms, understood as communities and community-based hybrids, in terms of their institutional properties and the mechanisms by which they solve the universal problems of organizing and compare and contrast them with markets and hierarchies. Based on the three ideal forms-markets, hierarchies, and communities-as advanced by Adler (2001), I propose a framework for analyzing and mapping organizational designs. This study contributes to economic organization and organization theory by specifying ideal forms across a parsimonious set of dimension and deriving a set of analytically distinct hybrids at the intersection of the ideal types. It also contributes by identifying the main conditions that drive organizations' change of form. The theoretical discussion on community-based forms is illustrated by three short empirical cases within the domains of drug discovery, software development, as well as professional services. I also discuss plural forms and the role of hierarchy in collaborative forms. Finally, I outline implications for research and practice in terms of comparative analysis of organizational forms, the role of crowds, as well as technology as enabler for new organizational forms.

\section{Community organizational forms}

How to organize and govern productive activity is a central question in organization science and economics (e.g., Arrow 1974; Simon 1991; Williamson 1975). It concerns core issues such as decision rights, make-or-buy considerations, resource ownership and allocation, contracting, knowledge sharing, and other forms of cooperation (e.g., Gulati and Singh 1998; Jensen and Meckling 1976). The majority of studies on comparative analysis of organizational forms in the economic organization literature has been based on two ideal forms-markets and hierarchies-and combinations of the two, called hybrids (Williamson 1979). This has proven to be a very powerful and robust analytical framework in settings where an industrial logic is dominant (Shelanski and Klein 1995). With the emergence of the knowledge and network economy, the market-hierarchy pair has become increasingly incomplete. Some have argued for a "swollen middle" (e.g., Hennart 1993; Zenger and Hesterly 1997, p. 210)—an increasing volume and diversity of market-hierarchy hybrids-while others have made the case for a third organizational logic that is different from markets, hierarchies, or any combination thereof (Bradach and Eccles 1989; Ouchi 1980; Powell 1990). Emphasizing the increasing importance of trust and collaboration in the knowledge economy, Adler (2001) put forward community as the third ideal type, which excels at collaborative knowledge production and with trust as the main coordination mechanism (Adler et al. 2008; Heckscher and Adler 2006).

Using Adler's typology as starting point and building on the burgeoning literature on community and collaborative organizational forms (e.g., Benkler 2002; Lee and Cole 2003; O'Mahony and Ferraro 2007), I define and discuss the community ideal form, in 
comparison to hierarchies and markets and propose a framework for comparative analysis of organizational forms as a synthesis. I also present an illustrative case of a community.

A community is an organizational form that enables and enhances networking among autonomous and interdependent participants-it entails membership, commitment to shared goals and purposes, and rules for participation (Heckscher and Adler 2006; Snow et al. 2011). Such designs enable large groups of participants to collaboratively solve problems and integrate their contributions in a self-organizing fashion, implying that they accomplish coordination and control primarily via direct interaction among themselves rather than by hierarchical subordination. Work is characterized by self-assignment to tasks and commons-based peer production (Benkler 2002; Lee and Cole 2003).

The institutional properties and design principles of communities differ from the other ideal forms in important ways. Hierarchies are organizational systems where units are ordered such that lower-level units are parts of, or subordinated to, units on the immediate higher level (Aoki and Jackson 2008; Simon 1962). Hierarchical organizations employ a set of structural principles for organizing tasks, resources, and information flows. It relies on authority as the main coordination mechanism as that higher-level units have decision and conflict-resolution authority over lower-level units (March and Simon 1958)-implying that its design is expressed in its authority structure (Simon 1962). A market ${ }^{1}$ is an arena in which autonomous parties engage in exchange (Williamson 1996, p. 378) with price as the main coordinating mechanism (Bradach and Eccles 1989; Hayek 1945). The design of a market is embedded in the institutions guiding information flows, price formation, exchange, and enforcement of rules and regulations (North 1990).

Communities rely on institutional mechanisms, analogous to the macro-level institutions of markets, as actors self-organize guided by shared values, rules, and protocols (Fjeldstad et al. 2012; Ostrom 1990). The protocols provide actors with the guiding principles to self-organize, effectively identify and mobilize collaborators and resources, collaboratively solve problems, share knowledge and ideas, and distribute rewards. Through shared values and norms, actors know what they can expect from fellow community members-providing a basis for trust-based collaboration (Adler et al. 2008). They affiliate with the community via some form of membership (Snow et al. 2011), while participants in markets and hierarchies affiliate via market contracts and employment, respectively (Simon 1991; Williamson 1975).

Community forms of organization are found in a wide range of domains such as open source software with Linux and Apache as prominent examples (Lakhani and von Hippel 2003; von Hippel and von Krogh 2003), open science initiatives such as The Human Genome Project (Collins et al. 2003), and the online encyclopedia Wikipedia which has become the undisputed leading encyclopedia globally (Aaltonen and Lanzara 2015). In the following, I present Open Source Drug Discovery (OSDD), an example of a community close to the ideal form. It involves collaborative knowledge production and scientific discovery. The example highlights the mechanisms involved in organizing complex problem solving in a large-scale community.

\section{Community example: Open Source Drug Discovery}

Open Source Drug Discovery is a collaborative community established to discover and develop affordable drugs for patients suffering from neglected infectious diseases such as tuberculosis (TB) and malaria. OSDD leverages the collective capabilities of an open and diverse community of experts and volunteers within computational and wet lab 
biology and chemistry, informatics, pharmacology, and clinical medicine. The community was founded in India in 2008, consists of more than 8000 participants from more than 130 countries, and selected TB as the first target area. In 2016, TB claimed about 1.2 million lives worldwide, no new mainstream TB drugs have been launched for 40 years, and problems with drug resistance are increasing (WHO 2017). The OSDD community model represents a radically different approach compared to those of the pharmaceutical industry as well as public and NGO research, which has shown to be insufficient in battling neglected diseases (Trouiller et al. 2002).

OSDD is based on open participation, open peer review, and open source intellectual property rights (IPR) principles (Sugumaran 2012). Participants share their results and data openly in the community commons where the online collaboration and knowledge-sharing platform SysBorg 2.0 plays a central role. OSDD's commons comprise a heterogeneous set of physical and intangible resources: biological and chemical data, chemical compound libraries, biological samples and assays, research protocols and lab notebooks, and ideas and project proposals. The community has identified 3540 novel drug targets, has projects along the different stages of the drug discovery process, and got its first phase $2 \mathrm{~b}$ clinical trial approved in March 2014. ${ }^{2}$

In OSDD, anyone who accepts the community's terms of use can join. The rules specify terms for using and contributing data, attribution of scientific results, as well as protocols for collaborative interactions. Individuals and teams of researchers pursue a wide variety of hypotheses for biological mechanisms and potentially active chemical compounds at their own choosing, which result in a greater diversity of potential solutions than what can be expected from conventional public and commercial research groups. The ability to mobilize a diversity of actors and contributions is particularly useful in a complex and experimental problem solving effort such as OSDD. The OSDD example highlights how a community enables a large and diverse set of actors to self-organize in the pursuit of a shared goal by means of shared values, rules, and protocols, as well as shared resources.

Community members unite around shared goals and purposes-e.g., the members of OSDD join forces to cure neglected diseases and provide affordable healthcare for all. In the ideal-type hierarchy, actors work to fulfill the goals of the owner(s). The owner incentivizes employees to align their goals to her own and monitor that they are fulfilled (Jensen and Meckling 1976). In markets, actors pursue their own goals independently.

Commons, and the associated common-property regime, are a distinguishing feature of communities (Benkler 2002; Lee and Cole 2003). Commons, or common-pool resources (CPR), are shared resources that are built, managed, and used by a community and may consist of physical or of intangible resources, such as knowledge (Ostrom 1990; Ostrom and Hess 2006). Members of a community-and membership can be open or restrictedcan access and use the resources in the commons freely according to shared rules and norms (Levine 2006; Ostrom 1990). In the market, resources are owned by the market participants and transacted when buyers and sellers agree on a price. In the hierarchical form, the organization and its owner(s) own the resources. In short, both markets and hierarchies operate under a private-property regime (Demsetz 1967) where market actors exchange assets and property rights and hierarchical organizations employ private property in their productive processes, while communities collectively build, maintain, and use shared resources according to a common-property scheme (Benkler 2002; Ostrom 1990). The institutional properties of the three ideal forms are summarized in Table 1 below. 
Table 1 The three ideal organizational forms: core institutional properties

\begin{tabular}{llll}
\hline & Market & Hierarchy & Community \\
\hline Locus of design & Market institutions, contracts & Authority structure & $\begin{array}{l}\text { Values, rules, and } \\
\text { protocols }\end{array}$ \\
Goals & Actor-specific goals & $\begin{array}{l}\text { Owner's goals, efforts to achieve } \\
\text { goal alignment among actors/ } \\
\text { organizational members }\end{array}$ & $\begin{array}{l}\text { Shared goals and } \\
\text { values }\end{array}$ \\
$\begin{array}{l}\text { Resource } \\
\text { ownership; } \\
\text { property rights } \\
\text { regime }\end{array}$ & $\begin{array}{l}\text { Actors own resources (and } \\
\text { can exchange them); private- } \\
\text { prfiliation }\end{array}$ & $\begin{array}{l}\text { Owner/organization owns } \\
\text { resources; private-property regime }\end{array}$ & $\begin{array}{l}\text { Shared resources in } \\
\text { commons; common- } \\
\text { property regime }\end{array}$ \\
\hline
\end{tabular}

The universal problems of organizing

Following from the institutional properties of the different ideal forms, they, respectively, feature widely different solutions to the universal problems of organizing as synthesized by Puranam et al. (2014) based on classic works on organization design (e.g., Burton and Obel 1984; Lawrence and Lorsch 1967; March and Simon 1958; Mintzberg 1979): task division, task allocation, reward distribution, and information provision. In the following, I elaborate how communities solve the four universal problems contrasted with the other ideal forms. The review is summarized in Table 2.

\section{Task division}

In hierarchies, the task structure is defined by managerial decision and exposed selectively to organizational members as management sees fit. In markets, the scope of a transacted good is typically defined by the buyer, while the division of tasks involved in providing the good is decided by the supplier. In the ideal-type community, the task

Table 2 The three ideal organizational forms: solutions to the universal problems of organizing

\begin{tabular}{|c|c|c|c|c|}
\hline & & Market & Hierarchy & Community \\
\hline $\begin{array}{l}\text { Task } \\
\text { division }\end{array}$ & Task division & $\begin{array}{l}\text { Scope of transacted good } \\
\text { typically set by buyer, } \\
\text { division of tasks to provide } \\
\text { good by supplier }\end{array}$ & $\begin{array}{l}\text { Managerial decision } \\
\text { (authority), centralized }\end{array}$ & $\begin{array}{l}\text { Distributed identification } \\
\text { and division of tasks by } \\
\text { general members }\end{array}$ \\
\hline \multirow[t]{3}{*}{$\begin{array}{l}\text { Task } \\
\text { allocation }\end{array}$} & Assignment & $\begin{array}{l}\text { Bidding/price, decentralized } \\
\text { in dyads (can be facilitated } \\
\text { by centralized platforms) }\end{array}$ & $\begin{array}{l}\text { Managerial decision } \\
\text { (authority), centralized }\end{array}$ & $\begin{array}{l}\text { Self-assignment, } \\
\text { decentralized (can be } \\
\text { facilitated by centralized } \\
\text { platforms) }\end{array}$ \\
\hline & $\begin{array}{l}\text { Resource } \\
\text { allocation }\end{array}$ & Price mechanism & $\begin{array}{l}\text { Managerial decision } \\
\text { (authority) }\end{array}$ & $\begin{array}{l}\text { Actor-based mobilization } \\
\text { of shared resources in } \\
\text { commons }\end{array}$ \\
\hline & $\begin{array}{l}\text { Quality/task } \\
\text { approval by }\end{array}$ & Customer & Manager & Peer \\
\hline $\begin{array}{l}\text { Reward } \\
\text { distribution }\end{array}$ & Incentives & $\begin{array}{l}\text { Compensation for outputs } \\
\text { via price mechanism } \\
\text { (strong) }\end{array}$ & $\begin{array}{l}\text { Typically compensation } \\
\text { for inputs (e.g., time) } \\
\text { (weak) }\end{array}$ & $\begin{array}{l}\text { Benefits from use of } \\
\text { complementary, non-rival } \\
\text { goods; other intrinsic and } \\
\text { extrinsic rewards (weak) }\end{array}$ \\
\hline \multirow[t]{2}{*}{$\begin{array}{l}\text { Information } \\
\text { provision }\end{array}$} & $\begin{array}{l}\text { Information } \\
\text { flow }\end{array}$ & $\begin{array}{l}\text { Via networks, information } \\
\text { intermediaries (private and } \\
\text { public) }\end{array}$ & $\begin{array}{l}\text { Directed, primarily } \\
\text { vertical }\end{array}$ & $\begin{array}{l}\text { Transparent, via networks } \\
\text { and commons }\end{array}$ \\
\hline & $\begin{array}{l}\text { Information } \\
\text { aggregation via }\end{array}$ & $\begin{array}{l}\text { Price mechanism, market } \\
\text { intermediaries and } \\
\text { information aggregators }\end{array}$ & Hierarchical channels & $\begin{array}{l}\text { Commons, collective } \\
\text { problem, and solution } \\
\text { representations }\end{array}$ \\
\hline
\end{tabular}


structure is designed and elaborated by community members in a distributed, self-organized fashion and transparently exposed, such as with Wikipedia where anyone can identify the need for a new encyclopedic entry as well as additions or corrections to current entries (Aaltonen and Lanzara 2015). While it is not uncommon in communities that basic task division is performed by actors in organizer roles such as project leaders and architects in OSS communities (Lee and Cole 2003), this could be viewed as a limited infusion of a hierarchical mechanism rather than a property of the community ideal form. One can observe both approaches to task division in OSDD where some challenges are defined by principal investigators, while other are identified by ordinary members as there are no restrictions on who can identify new tasks or problems for themselves or others to solve.

\section{Task allocation}

A task hierarchy is the successive decomposition of tasks into more specialized ones that on the lowest level can be performed by an individual or a team (Simon 1962). Markets allocate tasks via the price mechanism. Community participants themselves decide which tasks to take on (Benkler 2002), rather than being assigned tasks from superiors in a hierarchy (Thompson 1967). The ideal forms also differ in who approves the quality of accomplished tasks. Communities practice peer-based quality assurance (Lee and Cole 2003), while managers and customers approves quality in hierarchies and markets, respectively.

Resource allocation typically follows the task allocation logic. By means of the price mechanism, a market allocates resources to the highest bidder. Prices dynamically adjust to reflect changes in preferences, expectations, quality, risk, supply, and demand (Hayek 1945). In the hierarchical form, the organization and its owner(s) own the resources. The management allocates resources down through the ranks through direct allocation or delegation (Thompson 1967). Communities leave resource allocation to their members. They reveal resources transparently, make them openly available in the commons, and members mobilize these resources at will. It is the combination of transparency, shared rules and protocols, actor-initiated mobilization of shared resources, and self-assignment to tasks that enable community participants to self-organize at scale.

In the case of OSDD, members contribute by posting ideas, data, and materials to the commons that may advance the collective knowledge on a disease, potential cures, and the resources to use this knowledge. The community commons comprise a heterogeneous set of physical and intangible resources. The community collectively contributes to, stewards, and uses resource commons that grow and evolve over time. There are protocols, processes, and rules that regulate such sharing and the use of the contributions. In summary, markets, hierarchies, and communities allocate resources by means of the price mechanism, authority, and rules-based use of the commons, respectively.

\section{Reward distribution}

Furthermore, the ideal forms differ in the incentives they provide. Via the price mechanism, markets provide actors with high-powered incentives, i.e., they have clear entitlement to and can establish the magnitude of their returns easily based on their outputs (Williamson 1975). Hierarchical forms provide weaker incentives and typically 
compensate actors based on their inputs, such as number of hours worked. Community members appropriate value from their production and use of complementary, non-rival resources in the commons, professional status, as well as other intrinsic and extrinsic benefits (Lerner and Tirole 2002; Snow et al. 2011; von Hippel and von Krogh 2003). For example, in OSDD, there are detailed authorship rules regulating who are to be attributed as authors of academic work and in what order. Attribution rules do not distinguish on the basis of the seniority of the researchers. These rules and their consistent application are reported to have a motivational effect on students and junior researchers (Kolbjørnsrud 2017).

\section{Information provisioning}

All forms of economic organization process information to fulfill their purpose but employ different mechanisms for transmitting, filtering, aggregating, validating, interpreting, and searching for information (Felin and Zenger 2011; Galbraith 1974). In markets, prices aggregate idiosyncratic and local knowledge and expectations from dispersed actors about supply, demand, quality, risk, and more generally the value of products and services (Hayek 1945). Economic actors-with potentially diverging expectations and information-come together and prices dynamically coordinate their actions and interactions (Felin and Zenger 2011, p. 164). Markets are efficient when products and services are easily transactable and prices can be determined with moderate effort, i.e., under conditions of many buyers and sellers, unhindered flow of information, low asset specificity, and in the absence of serious market failures (Stiglitz 1989; Williamson 1975). A hierarchical organization structure is an information processing system in itself. Higher-level units have broader access to information and filter and communicate information relevant to specific subordinate units in the form of requirements, plans, rules, etc. (Galbraith 1974). Subordinate units report operational information to superior units. The hierarchy is an effective means for enabling routine vertical information flows that can be designed into its stable structure. Nevertheless, speed and adaptiveness is not its strong suit as hierarchies tend to suffer from filtering and delays and are poorly equipped for routing and processing non-routine information (Galbraith 1974).

Communities rely heavily on commons for information flow and processing. In principle, all relevant information is shared in commons and therefore available to all members. Information transparency enables self-assignment as participants have access to the problems and opportunities the community faces, the resources at their disposal, and the identities and capabilities of potential collaboration partners (Autio et al. 2013; Puranam et al. 2014). This allows members to choose where they can contribute the best and to work on what they find most rewarding.

In the OSDD example, information flows are guided by protocols structuring communication and specifying submission, storage, and retrieval standards for the commons. Technology-enabled protocols and processes guide search for data, resources, and potential collaborators allowing participants to filter and identify the most relevant information before initiating any manual information processing. The search protocols and tools increase the information processing capability and capacity of the community enabling it to scale while mitigating the risk of information overload.

Communities also face information flow and processing issues. First, members may choose to withhold relevant knowledge and free ride (Baldwin and Clark 2006). Second, 
information quality variance can be high as any member can contribute without ex ante approval. Third, the information available to members may be so vast that they are not able to find, share, or combine the right information even if they wanted to (Benkler 2006). Communities mitigate the first hazard through shared goals, values, rules, and incentive structures combined with extensive transparency that is conducive to trust, reciprocity, and expectations of fairness (Lerner and Tirole 2002; Ostrom 2000). Peer review assures the quality of information (Benkler 2002). Finally, communities deal with potential information overload by structuring the commons and applying protocols and tools for search, broadcasting, and subscription to information.

Technology significantly impacts an organization's information processing capabilities and organization design opportunities (Simon 1973). Recent advances in information and communication technologies (ICT) enable new and enhanced organizational capabilities such as visualizing entire work processes, real-time and flexible product and service creation, virtual collaboration, crowd innovation, simulation and synthetic representation, location tracking, remote operation, and new forms of exchange (Boudreau and Lakhani 2013; Carroll et al. 2006; Griffith et al. 2003; Zammuto et al. 2007; Zervas et al. 2017). Technology also influences how economic actors build trust. First, contemporary digital social and exchange platforms enable unprecedented transparency. All actions create data and past and present behavior is traced automatically-dramatically reducing information asymmetries that could otherwise cause serious governance issues. Extensive transparency is a prerequisite for mutual monitoring which characterize peer-based governance in collaborative organizations, as well as it enables informed participants to self-assign to tasks (Kolbjørnsrud 2017; Puranam et al. 2014). Second, feedback and other forms of data coupled with algorithms provide the basis for ratings and other digital measures of quality, value, and trustworthiness (Dellarocas 2003; Pettersen 2017). While new ICT technologies can be used in any organizational form, arguably they tend to attenuate the reliance of hierarchical structures for information processing and governance and have been an important enabling factor in spawning new community and market forms of organizing (Daft and Lewin 1993).

In summary, the three ideal forms-community, market, and hierarchy-differ significantly across critical organizational dimensions. I have reviewed the institutional properties and solutions to the universal problems of organizing here and make the case for community as a form distinctly different from market, hierarchy, or any market-hierarchy hybrid as the community ideal form does not lend a single of its main properties and mechanisms from the market and hierarchy ideal types (summarized in Tables 1 and 2). The characteristics of communities make them particularly suited for collaborative knowledge production when the locus of knowledge is distributed across multiple actors (Adler et al. 2008; Powell et al. 1996), when the generation and governance of shared resources is critical (Benkler 2002; Ostrom 1990), and when actors have shared goals and the values and capabilities to self-organize (Adler et al. 2008; Miles et al. 2010).

\section{Hybrid forms}

Hybrids combine governance and coordination mechanisms from more than one ideal form (Seibel 2015; Williamson 1996). ${ }^{3}$ In the literature, hybrids have been equivalent to market-hierarchy hybrids such as joint ventures, franchising arrangements, and 
strategic alliances (e.g., Makadok and Coff 2009; Williamson 1979). But categorizing all organizational forms that neither are pure hierarchies nor pure markets as market-hierarchy hybrids represent a major loss in analytical accuracy, for at least two reasons. First, as my review has shown, community forms are fundamentally different from markets, hierarchies, or hybrids thereof and should not be classified as such. Second, acknowledging the existence of three ideal forms of organization also opens for a set of analytically distinct hybrids. As illustrated in Fig. 1 below, a tripolar view of comparative analysis of organizational forms allows for at least three major classes of hybrids-market-hierarchy, hierarchy-community, and market-community hybrids-or even combinations of all three ideal forms. Such a view enables us to study hybrid forms with greater conceptual clarity and analytical accuracy, particularly the collaborative, community-based hybrids which we will discuss more in depth in this section.

Most organizations have to satisfy multiple demands and make tradeoffs between potentially conflicting requirements such as efficiency and adaptiveness, control and trust, as well as exploration and exploitation (March 1991; Miles and Snow 1978; Puranam and Vanneste 2009). Only a fraction of organizational forms perfectly fits the description of an ideal form, and one could argue that most organizations are hybrids or lend mechanisms from more than one form (Hennart 1993). For example, while hierarchical forms are very common, very few organizations, if any, are governed exclusively by formal authority, or managerial "fiat" in Williamson's (1991, p. 274) terms. The presence and operation of trust (e.g., McEvily et al. 2003; Puranam and Vanneste 2009), informal organization (e.g., Gulati and Puranam 2009; McEvily et al. 2014), knowledge-sharing networks (e.g., Hansen 1999, 2002), and professional communities of practice (e.g., Van Maanen and Barley 1984; Wenger 1998) in hierarchical organizations are well documented and discussed in the literature. Viewed through the analytical lens of this paper,

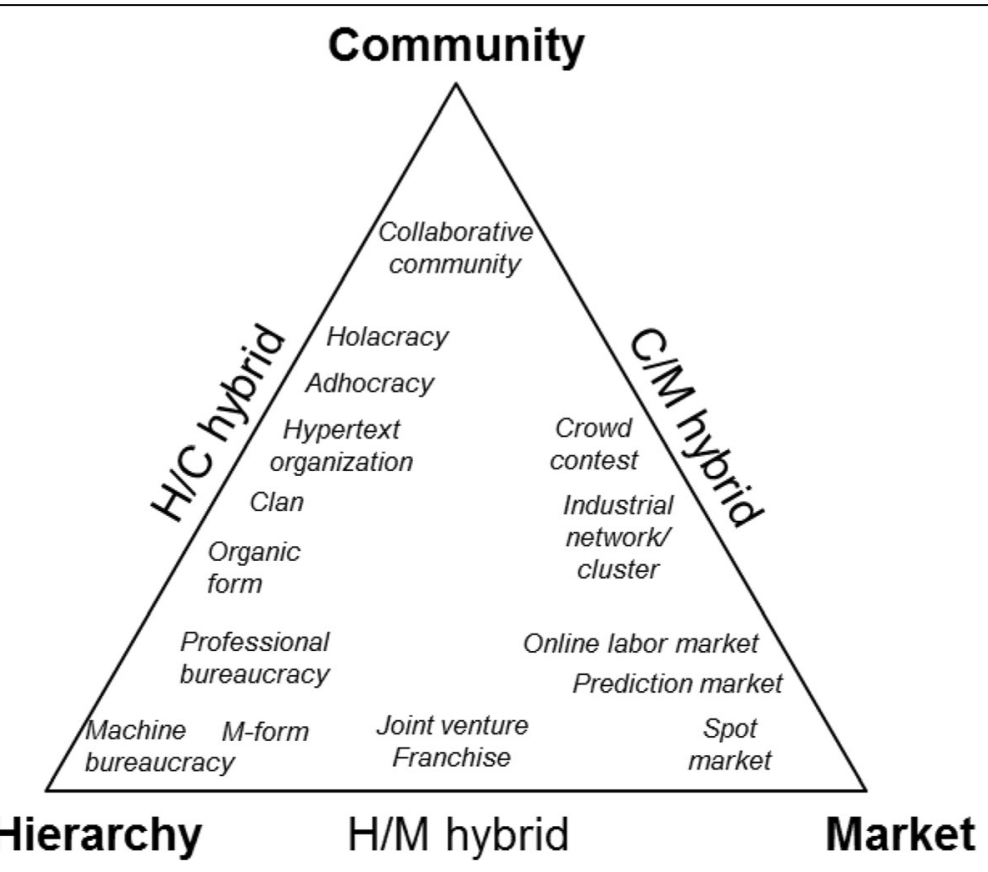

Fig. 1 Map of organizational forms with illustrative examples 
these phenomena are community mechanisms infused into predominantly hierarchical forms or characteristics of hierarchy-community hybrids.

If we start from the hierarchical corner of the triangular map of forms in Fig. 1, the machine bureaucracy is one of the known forms situated closest to the pure form (Mintzberg 1983). The M-form is a hierarchy that through mechanisms such as internal pricing borrows some properties of a market (Chandler 1962; Williamson 1996), while the professional bureaucracy (Mintzberg 1983) absorbs some community traits via the values and codes of professions and knowledge-based power rivaling managerial authority.

Moving along the hierarchy-community axis, one could classify the organic form (Burns and Stalker 1961), the clan (Ouchi 1980), and the hypertext organization (Nonaka and Takeuchi 1995) as hierarchy-community hybrids. Mintzberg's (1983) adhocracy is quite loosely defined and could capture a variety of hierarchy-community hybrids toward the community end of the spectrum and even cover some community forms. Recently, there has been much attention around Holacracy in the business press and in practitioner journals, with the online retailer Zappos as the most prominent example (Bernstein et al. 2016). Holacracy is an organizational system of self-organizing teams designed to simplify operations, streamline workflows, and increase transparency. While open source software (OSS) communities are often described as near the ideal type, some studies point out that they may selectively adopt hierarchical properties such as a limited form of a management hierarchy for certain organizational governance functions (O'Mahony and Ferraro 2007).

Many markets do not fit the description of the archetypical atomistic version. Markets are social structures where relationships and reputation matters (Ahrne et al. 2014; Granovetter 1985). Networks influence flows of information, knowledge, ideas, opportunities, resources, and trust in markets (e.g., Ahuja 2000; Burt 2004; Coleman 1988; Powell et al. 1996). Uzzi's (1997) study of the New York City fashion industry is a case in point. The role of trust, norms, social control, and enforcement in many markets suggests that they exhibit important community mechanisms. Tightly knit industry clusters and interorganizational learning networks, as in the Italian design and the biotechnology industries (Capaldo 2007; Powell et al. 2005), can be understood as market-community hybrids. Knowledge spillovers, shared talent pools, network effects, and agglomeration economies among interdependent competing and collaborating actors characterize clusters (Audretsch and Feldman 1996; Porter 1990) and demonstrate blends of market and community mechanisms.

\section{Collaborative, community-based hybrid forms}

In this article, collaborative organizational forms refer to communities and community-based hybrids populating the upper corner of the triangle in Fig. 1. We are currently seeing significant innovation in organizational forms close to the community ideal type. In the following, I describe and discuss two illustrative empirical examples of collaborative hybrid forms; first, TopCoder, a community-market hybrid, and then Accenture, a community-hierarchy hybrid.

\section{Community-market hybrid example: TopCoder}

Crowd contests are increasingly popular means of seeking novel solutions to problems by challenging large and diverse sets of individuals, or small self-forming groups, that 
are typically unaffiliated with the solution-seeking party (Lakhani et al. 2013). Such contests usually involve three sorts of actors: (1) the party that has a problem they want the crowd to solve, (2) the "crowd" of problem solvers, and (3) the platform that recruits participants and facilitates the crowd contest (Bingham and Spradlin 2011). Tasks are defined by the solution-seeking party, typically in collaboration with the contest organizers, in the form of a specific problem to be solved. The challenge is announced on the crowd contest platform along with a prize. For each challenge posted, the participants compete with alternative solutions, and the solution-seeking party assesses the entries and selects who-so long as anyone meets the criteria-has provided the best solution and will be awarded the prize. While each contest is restricted to a particular task or problem, it draws participants from the same community of problem solvers and are enabled by the same organizational architecture-such as technical platform, competition rules, and protocols-as the other contests on the same platform.

TopCoder is a crowd contest platform in the design and software domain. It was founded in 2001 and hosts a community of more than a million designers, developers, and data scientists worldwide and more than 7000 crowdsourcing challenges per year (TopCoder.com 2018). For example, TopCoder is one of NASA's most frequently used partners for coding and algorithmic challenges. The US space agency has since 2010 systematically experimented with crowd contests in solving problems that its own organization does not have the capacity or ability to resolve. The "Asteroid Tracker Challenge" is one such example. The problem was to develop optimization algorithms for how to allocate the capacity of NASA's radar dishes around the world, i.e., which radar dish should follow which Near Earth Object. The crowd contributions via TopCoder advanced NASA's capabilities needed for the continued development of its management of radar arrays to track and categorize asteroids more effectively (NTL 2018).

Crowd contest platforms à la TopCoder are effective means for sourcing novel solution ideas from large and diverse sets of experts and hobbyists-as diversity often trumps expertise in problem solving due to it improving exploratory search (Afuah and Tucci 2012; Hong and Page 2001; Jeppesen and Lakhani 2010). They are distinguished from collaborative communities, which are close to the community ideal type, as participants develop potential solutions to standalone problems and do not participate in selecting winning contributions. In collaborative communities, members participate in the whole problem solving processthrough problem definition, generation of alternatives, selection and integration of solutions. Here, the problem often is more complex, the process cumulative, and the community commons play an important role (Lee and Cole 2003). Crowd contests are hybrids that combine market and community mechanisms. Contest participants compete for the prizes and status associated with winning and they often collaborate as they team up for challenges and share knowledge between contests (Boudreau and Lakhani 2013; Hutter et al. 2011). Such contests function as two-sided markets for ideas (Poetz and Schreier 2012; Rochet and Tirole 2003). The price mechanism, in the form of monetary prizes, is complemented by status and learning benefits (Zheng et al. 2011) - where a monetary prize is also a signal of the former.

\section{Community-hierarchy hybrid example: Accenture}

Accenture is a technology and professional services company providing technology and business consulting as well as outsourcing services. Its 449,000 employees serve large clients in more than 120 countries worldwide (Accenture 2018). The company 
combines community and hierarchical design elements in its organization. There are significant scale and scope benefits to be realized form a diverse, distributed, and skilled global workforce in selling, developing, and delivering client projects. Collaborations can be brief or long term, co-located or virtual, local or global depending on the client, the nature of the problem to be solved, and the availability and location of the required expertise. Accenture uses online platforms for staffing, knowledge sharing, and communication. It invests in developing shared values, methods, and skill sets in its workforce to enable and simplify collaboration across units, as well as in protocols and infrastructures to support it. For example, if a project manager in France needs a US-based expert on a project, the manager may identify the expert through the Knowledge eXchange (KX) and People@Accenture-the company-wide knowledge management and people directory systems, respectively-approach the person directly and recruit for the project at hand. An HR professional typically supports the process, but it does not pass through the full chain of command. The manager instantly knows the cost of the expert by entering the person's name in the sales support and budgeting system, and by allowing the expert to charge hours worked to a project account the expert's utilization and profitability metrics are credited. The infrastructures and organizational protocols enable actor-level and near seamless workforce identification, mobilization, collaboration, and compensation across units and geographies. Accenture uses its hierarchical management structure for setting strategic direction, control, and conflict resolution, hence combining community and hierarchical design mechanisms into a collaborative architecture (Fjeldstad et al. 2012).

\section{Changing organizational form}

An organization may evolve its form over time. The tripolar framework and the discussion of ideal and hybrid forms above can help us understand the forces driving an organization from one form toward another. The emergence and need for shared goals and resources are moving organizations toward community and community hybrid forms. Companies that need to improve their adaptiveness, innovativeness, and ability to solve increasingly complex problems tend to adopt coordination and control mechanisms associated with community forms in order to enhance collaboration and knowledge sharing within and across boundaries, as highlighted in the classic case of Oticon (O'Keefe and Lovas 2002; Puranam et al. 2014). In markets that would benefit from complementary, non-rival resources, such as shared standards, or trustful, repeated exchanges tend to develop community traits. Blade.org, a collaborative community of firms where IBM, Citrix, Intel, and more than 70 other technology firms that jointly developed blade server solutions (Snow et al. 2011), is a case in point. Hierarchical mechanisms are appropriate in settings that require more control, direction, and orchestrated action when actor goals are not sufficiently aligned such as in markets when establishing strategic alliances or acquiring actors with critical resources (Hart 1995; Williamson 1979) or by selectively introducing hierarchical governance mechanisms in communities (O'Mahony and Ferraro 2007). Finally, organizations tend to selectively adopt the price mechanism - the defining feature of markets-to improve resource allocation efficiency, strengthen incentives, and enhance flexibility (Zenger and Hesterly 1997). Examples include transfer pricing in multi-business firms (Eccles and White 1988) and monetary prizes in crowd contests (Morgan and Wang 2010). The forces driving organizations to adopt coordination and control mechanisms from other forms than their current and move within the tripolar framework are illustrated in Fig. 2. 


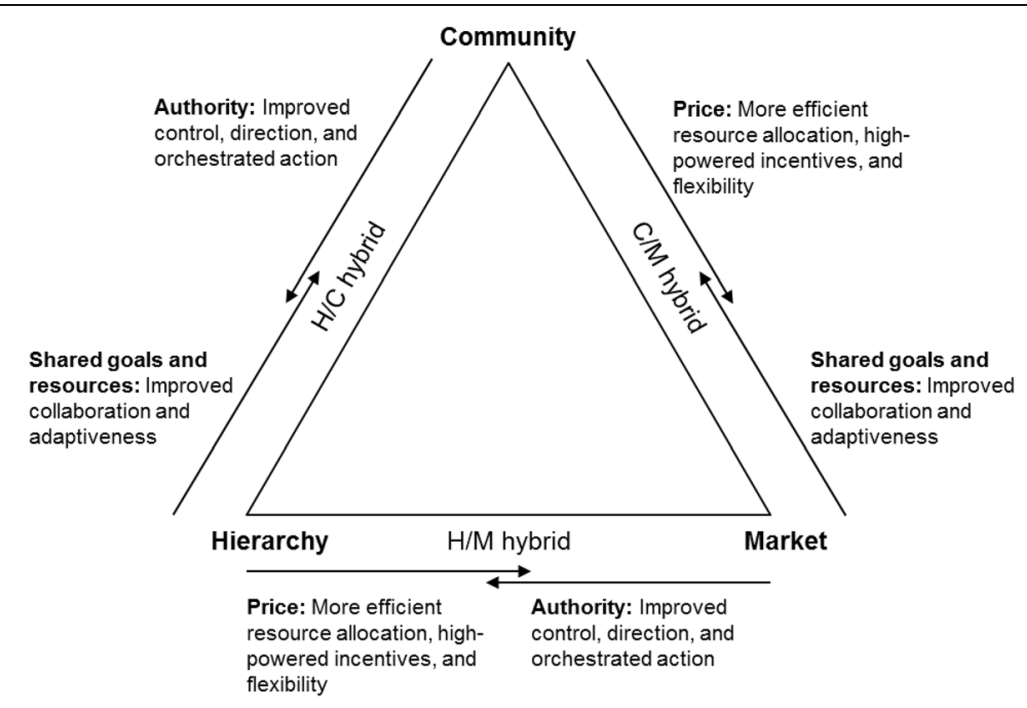

Fig. 2 Forces driving change in organizational form

\section{Plural forms}

In addition to combining different mechanisms into hybrid forms, organizations frequently employ plural forms. Plural forms refer to where an organization simultaneously operates distinct and different control mechanisms in the same organizational structure to perform the same function-with retailers that operate both franchises and company-owned units under the same brand as a classic example (Bradach and Eccles 1989, p. 99). The TopCoder example above shows that NASA, one of the world's most recognized innovative research and development (R\&D) organizations, has found it necessary to engage in systematic and large-scale crowdsourcing in addition to its internal efforts. The space agency combines a heterogeneous portfolio of internal and external approaches-plural forms-for its $R \& D$ function: internal $R \& D$ departments, internal pan-organizational collaborative challenges, external crowd contests, and subcontracting of $R \& D$ projects. In a similar fashion, Accenture is experimenting with crowdsourcing and online labor market technologies in an effort to more effectively and efficiently leverage internal and external workforces. In these efforts, the company employs online labor market technology to facilitate brokering of micro tasks among internal employees. It complements the ordinary project staffing practices, mediating small tasks and personnel that are not on full-time projects, which enables better workforce capacity utilization, assistance for the requester, and learning opportunities for the employee. The company is considering to combine the internal crowdwork platform with external online labor market providers as well as to establish a "privately curated, external crowd" of workers that are pre-vetted, such as company alumni and contractors (Kass 2016). Both the NASA and Accenture efforts exemplify plural forms, but while the NASA highlights how an organization can apply a variety of mechanisms for performing the same function internally and externally-in this case R\&D-the Accenture case demonstrates how the same mechanism-online labor markets-can be used to identify and mobilize both internal and external workforces. 
The role of hierarchy in collaborative forms

Hierarchical structures and patterns are not necessarily absent from collaborative organizational forms. While not the dominating organizing scheme, we observe hierarchy in two principal ways in such contexts. First, hierarchical coordination and control mechanisms are present in community-hierarchy hybrids as discussed above. Second, even though formal hierarchical authority structures may be absent, status hierarchies, network centrality and periphery structures, and other patterns causing asymmetric distribution of power, influence, information, and resource access are usually present. In the case of OSDD, a handful of organizers and principal investigators had a strong influence on the direction of the community and the peer reviews of recognized experts would carry more weight than that of a novice student even though every member could, and was encouraged to, provide their reviews on any contribution to the community. However, such hierarchical patterns in social structure and interaction should not be confused with hierarchy as an organization design and governance scheme.

\section{Discussion and implications}

In this article, I describe and explain collaborative organizational forms, i.e., communities and community-based hybrids, compare and contrast their institutional properties and organizational mechanisms with those of markets and hierarchies. I synthesize the findings in an analytical framework based on three ideal forms-markets, hierarchies, and communities showing that including community as the third ideal type is necessary and useful for analyzing and understanding collaborative organizational forms. The framework allows us to derive a set of analytically distinct hybrids at the intersection of each pair of the ideal types or even all three combined. It also helps us understand the conditions driving an organization from one form toward another. I place particular emphasis on the variety and characteristics of new collaborative forms at the community end of the triangular framework in the theoretical review and in exploring three empirical cases within the domains of drug discovery, design and software development, as well as professional services. In the following, I outline implications for research and practice in terms of comparative analysis of organizational forms, the role of crowds, as well as the interplay between new technologies and new organizational forms.

First, this study has implications for the literature on comparative analysis of organizational forms and how these forms interplay in hybrids. It specifies the distinguishing features of the ideal forms and identify the main forces and conditions driving toward hybrid forms. The study elaborates the repertoire of design mechanisms available for organization designers and features empirical examples of collaborative forms-communities and community-based hybrids-highlighting the practical relevance of the theoretical discussion.

The tripolar framework uses the three ideal-typical forms in Adler (2001) as starting point and extends it with insights from the extensive subsequent literature on communities and collaborative forms. In line with Bradach and Eccles (1989), Adler's (2001) study highlights trust as the main coordination mechanism and distinguishing feature of communities. Based on more recent community literature, I specify the combination of shared goals, shared resources-and the associated common-property regime-as 
well as rules-based self-organization as the defining characteristics of the community ideal type and which are conducive to trust (Adler et al. 2008; Benkler 2002; Fjeldstad et al. 2012). I apply Puranam et al.'s (2014) synthesis of organizational forms as providing solutions to the four universal problems of organizing to structure the discussion of the key coordination and control mechanisms of the ideal types. However, the purpose of this study is different from theirs. While Puranam et al. (2014) focuses on what makes new organizational forms different from extant forms, this study seeks to explain collaborative forms by specifying the distinctive properties of communities compared to the other ideal types as well as explain the nature and dynamics of hybrids and community-based hybrids in particular. In applying their taxonomy, I also emphasize the role of resource ownership and allocation and, hence, integrate a seemingly missing perspective in Puranam et al. (2014).

This study highlights the role of institutional mechanisms in governing collaborative organizational forms. Institutional governance-in terms of shared values, rules, and protocols-guides, rather than directs, participant behavior. Combined with shared goals, commons, and extensive transparency, they enable and regulate self-organization at scale. This highlights the synergistic interplay between formal and informal organization in community-based organizations. The deliberate, formal design enables emergent organizational behavior (Fjeldstad et al. 2012), in contrast to the decoupling between formal mechanisms and institutionalized, informal practices often found in organizations (Meyer and Rowan 1977). Studies of other organizational forms show that trust and formal governance can have both complementing and substituting effects on each other (Puranam and Vanneste 2009). In communities, one can expect formal, yet non-hierarchical, mechanisms to enable and enhance trust as suggested by recent studies (e.g., Kolbjørnsrud 2017). Further research is needed to decipher the relationship between formal, non-hierarchical governance and trust in communities under different conditions.

Any conceptual framework is a simplified representation of the world. While capturing significantly more of the variation than the classic market-hierarchy framework, to illustrate the full variety of hybrid forms within a triangular plane (as in Fig. 1) is also a simplification. It is more likely a multidimensional space that would allow for nearly limitless variation in hybrid forms.

The study contributes to the literature on configurational approaches to organizational analysis (Fiss 2011; Miles and Snow 1978; Mintzberg 1983; Short et al. 2008). The ideal types are organizational configurations-commonly occurring multidimensional constellations of conceptually distinct organizational characteristics (Meyer et al. 1993, p. 1175). In the literature on market-hierarchy hybrids, we find numerous examples of hybrid configurations such as franchise arrangements and different forms of strategic alliances (Borys and Jemison 1989; Shane 1996; Williamson 1991) and it is reasonable to expect this to be the case with community-based hybrids as well. For instance, a recent study found open membership to co-occur with extensive peer review in collaborative communities, while community hybrids with less peer review for quality assurance tend to employ membership restrictions-trading off input and output controls (Kolbjørnsrud 2017). Furthermore, crowd contests typically employ configurations of mechanisms that are very similar to each other (Lakhani et al. 2013; Zheng et al. 2011). Systematic analysis of community-based organizational configurations 
coupled with environmental contingencies-in terms of understanding which configurations are appropriate under different conditions as well as understanding which mechanisms that are mutually reinforcing or conflicting-is a potentially very fruitful avenue of research with important theoretical and practical implications.

Second, this study contributes to our understanding of how a range of new organizational forms draws on the proverbial wisdom of the crowd. Prediction markets aggregate the knowledge and expectations of a crowd in order to make more accurate predictions of uncertain future events (Wolfers and Zitzewitz 2004). Crowd contests harness the diverse knowledge, experience, and creativity of a crowd to generate novel solutions to defined problems (Lakhani et al. 2013). In collaborative communities, crowds collaboratively solve complex problems and integrate their contributions into solutions (Kolbjørnsrud 2017). From the perspective of organizing as differentiation and integration (Lawrence and Lorsch 1967), all the forms of crowdsourcing discussed here are capable of achieving very high levels of differentiation, but they differ widely in the degree of and approach to integration. Collaborative communities integrate diverse contributions into solutions by means of collaborative processes and the commons (Benkler 2002; Lee and Cole 2003); crowd contests do not integrate contributions, but evaluate and select among them (Lakhani et al. 2013); and prediction markets aggregate knowledge and expectations through the price mechanism (Wolfers and Zitzewitz 2004). The crowd varieties are distributed along the community-market edge of the triangular framework as illustrated in Fig. 1. They may draw on the contributions of both experts and amateurs and may focus on mobilizing communities composed of individuals with high or low levels of specialized expertise, or a full range. OSDD did the latter, utilizing the competence and capacity of contributors from undergraduate students to world-class scientists. There is increasing recognition of the potential for utilizing crowdsourcing mechanisms also within more conventional organizations, which the Accenture internal online labor market for micro tasks discussed above indicates. More research is needed on how crowd composition may influence the organization design and vice versa.

Third, new technology is an important source of novel solutions to the problems of organizing and as Burns and Stalker (1961, p. 19) stated: "Technical progress and organizational development are aspects of the same trend in human affairs." We have observed this in the recent past and the pace of technology development is not slowing. New technologies, such as artificial intelligence and distributed ledger technology, are emerging and could significantly impact economic organization and spur new forms of organizing.

Many researchers and futurists expect artificial intelligence (AI)-technologies that sense, comprehend, act, and learn-to revolutionize work and society over the next two decades (e.g., Brynjolfsson and McAfee 2014). The combination of AI and mobile robotics will make it possible to automate many types of manual and cognitive workparticularly of the routine type (Frey and Osborne 2017). Intelligent technologies can also augment human work such as in improving decision making, accelerate problem solving, and support human judgment (Daugherty and Wilson 2018; Davenport and Kirby 2016). AI can empower actors at the edges of the organization with knowledge and intelligence allowing them to become more autonomous in their work (Di Fiore 2018). Intelligent technologies will push the boundaries of organizational rationality, 
making it less "bounded" by removing information processing constraints. Until recently, organization theory has exclusively referred to actors as humans (or collectives of humans), but with the advancements in artificial intelligence, organization design may have to cater for the possibility of intelligent non-human organizational actors, hence, transforming organizations into collectives of intelligent human and non-human actors. These developments are likely to redefine the role of management and organizational governance (Kolbjørnsrud et al. 2016) and present major challenges as well as opportunities for organizational theory and research.

Distributed ledger technologies (DLT) - with Blockchain as the most prominent example-allows for a distributed, transparent tracing of transactions, assets, and contributions and reduce the need for intermediaries such as banks and brokers, and centralized monitoring and control as with governmental agencies (Iansiti and Lakhani 2017). DLT also provide means for tracing and managing digital property rights, as well as automate important performance and incentive management processes in organizations. DLT enable enhanced transparency and mutual monitoring which are essential mechanisms in market and community governance (Arrow 1974; Bowles and Gintis 2002; Lerner and Tirole 2002; Stiglitz 1990) and may lessen the need for hierarchical control in collective action and exchange.

While advances in information technology have been important enablers of new organizational forms, the relationship between technology and organizational form is not deterministic. The current wide adoption of internet-based communication technologies such as email, cloud storage, and video conferencing has enabled both distributed peer production as in OSDD and Open Source Software Communities as well as centralized governance of multinational enterprises. Similarly, one can expect that the new technologies discussed here will enable decentralized, actor-oriented work and governance, hence increase the feasibility and diversity of community and market organizational forms. However, one can also expect the very same technologies to allow increasingly centralized coordination of distributed actors through connectivity, information processing capabilities, and intelligent automation. While technology is important to the development of new organizational forms, as it expands and enhances the available repertoire for organizational design, it does not change organizations by default, but has to be accompanied with new organizational mechanisms and practices. Organization design is still the outcome of deliberate choices and the patterns emerging from the interactions among organizational actors (Dunbar and Starbuck 2006; Garud et al. 2006). As this is a fast-developing field, we need more research and experimentation on the role of technology as enabler of new organizational forms in general, and new collaborative forms in particular.

\section{Conclusion}

In this study, I have discussed a variety of new collaborative organizational forms that have emerged over the last couple of decades. It is hard to predict the future but there is little reason to expect that the pace of change will decelerate, quite the contrary. It is truly exciting times for organization scholars and practitioners as the means available for crafting new organizational forms are rapidly expanding-creating new opportunities and challenges. I hope that my review, synthesis, and proposals are able to inform and inspire further experimentation and research on new organizational forms. 


\section{Endnotes}

${ }^{1}$ Even though a market is not a formal organization in the conventional sense, it is a way of organizing economic activity; hence, throughout this review I call it an organizational form (Ahrne et al. 2014), which can be compared and contrasted to other organizational forms.

${ }^{2}$ OSDD lost its financing in 2014-2015 due to a change of government in India and in the leadership of CSIR, the sponsoring agency. The community is currently not operative but most of its problem-solving resources are still available and in use and several of the key participants in the community are central in the Open Source Pharma Foundation, an initiative to mobilize a global movement in open source drug discovery.

${ }^{3}$ Two main alternative perspectives on organizational hybridity exist in literature (Seibel 2015): (1) As combinations of governance mechanisms such as market-hierarchy hybrids and (2) as organizations/institutional arrangements located at the intersection between societal sectors such as social enterprises. I adhere to the first (no. 1) perspective in this article.

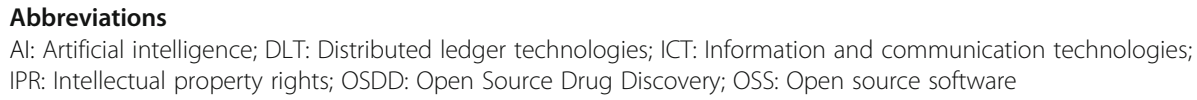

The author receives funding from Accenture-one of three organizations covered as illustrative case studies in the article. The funding company has not had any role in the design of the study, collection, analysis, and interpretation of data, or in writing the manuscript. The text and analysis is solely the author's.

\section{Publisher's Note}

Springer Nature remains neutral with regard to jurisdictional claims in published maps and institutional affiliations.

Received: 22 February 2018 Accepted: 9 October 2018

Published online: 19 October 2018

\section{References}

Aaltonen A, Lanzara GF (2015) Building governance capability in online social production: insights from Wikipedia. Organ Stud 36:1649-1673

Accenture (2018) Accenture.com. https://www.accenture.com. Accessed 14 Aug 2018

Adler PS (2001) Market, hierarchy, and trust: the knowledge economy and the future of capitalism. Organ Sci 12:215-234

Adler PS, Kwon SW, Heckscher C (2008) Professional work: the emergence of collaborative community. Organ Sci 19:359-376. https://doi.org/10.1287/orsc.1070.0293

Afuah A, Tucci CL (2012) Crowdsourcing as a solution to distant search. Acad Manag Rev 37:355-375

Ahrne G, Aspers P, Brunsson N (2014) The organization of markets. Organ Stud 36:7-27

Ahuja G (2000) Collaboration networks, structural holes, and innovation: a longitudinal study. Admin Sci Quart 45:425-455

Alberts DS, Garstka J, Stein FP (1999) Network centric warfare: developing and leveraging information superiority. In: CCRP publication series. National Defense University Press, Washington

Aoki M, Jackson G (2008) Understanding an emergent diversity of corporate governance and organizational architecture: an essentiality-based analysis. Ind Corp Change 17:1-27. https://doi.org/10.1093/lcc/Dtm037

Arrow KJ (1974) The limits of organization. WW Norton \& Company, New York

Audretsch DB, Feldman MP (1996) R\&D spillovers and the geography of innovation and production. Am Econ Rev 86:630-640

Autio E, Dahlander L, Frederiksen L (2013) Information exposure, opportunity evaluation, and entrepreneurial action: an

investigation of an online user community. Acad Manag J 56:1348-1371

Autor DH (2001) Wiring the labor market. J Econ Perspect 15:25-40 
Baldwin CY, Clark KB (2006) The architecture of participation: does code architecture mitigate free riding in the open source development model? Manag Sci 52:1116-1127. https://doi.org/10.1287/mnsc.1060.0546

Benkler Y (2002) Coase's penguin, or, Linux and the nature of the firm. Yale Law J 112:369-446

Benkler $Y$ (2006) The wealth of networks: how social production transforms markets and freedom. Yale University Press, New Haven

Bernstein E, Bunch J, Canner N, Lee M (2016) Beyond the Holacracy hype. Harvard Bus Rev 94:2-13

Bingham A, Spradlin D (2011) The open innovation marketplace: creating value in the challenge driven enterprise. FT Press, Upper Saddle River

Borys B, Jemison DB (1989) Hybrid arrangements as strategic alliances: theoretical issues in organizational combinations. Acad Manag Rev 14:234-249

Boudreau KJ, Lakhani KR (2013) Using the crowd as an innovation partner. Harvard Bus Rev 91:60-69

Bowles S, Gintis H (2002) Social capital and community governance. Econ J 112:F419-F436

Bradach JL, Eccles RG (1989) Price, authority, and trust: from ideal types to plural forms. Annu Rev Sociol 15:97-118

Brynjolfsson E, McAfee A (2014) The second machine age: work, progress, and prosperity in a time of brilliant technologies. WW Norton \& Company, New York

Burns T, Stalker GM (1961) The management of innovation. Tavistock, London

Burt RS (2004) Structural holes and good ideas. Am J Sociol 110:349-399

Burton RM, Obel B (1984) Designing efficient organizations: modelling and experimentation. Advanced series in management, vol 7, North-Holland Publishing Company, New York

Capaldo A (2007) Network structure and innovation: the leveraging of a dual network as a distinctive relational capability. Strategic Manage J 28:585-608. https://doi.org/10.1002/Smj.621

Carroll TN, Gormley TJ, Bilardo VJ, Burton RM, Woodman KL (2006) Designing a new organization at NASA: an organization design process using simulation. Organ Sci 17:202-214

Chandler AD (1962) Strategy and structure: chapters in the history of the industrial enterprise. M.I.T. Press Research Monographs. MIT Press, Cambridge

Child J, McGrath RG (2001) Organizations unfettered: organizational form in an information-intensive economy. Acad Manag J 44:1135-1148

Coleman JS (1988) Social capital in the creation of human capital. Am J Sociol 94:S95-S120

Collins FS, Morgan M, Patrinos A (2003) The human genome project: lessons from large-scale biology. Science 300:286-290

Daft RL, Lewin AY (1993) Where are the theories for the new organizational forms? an editorial essay. Organ Sci 4:i-vi

Daugherty PR, Wilson HJ (2018) Human + machine: reimagining work in the age of Al. Harvard Business Press, Cambridge

Davenport TH, Kirby J (2016) Only humans need apply: winners and losers in the age of smart machines. Harper Business, New York

Dellarocas C (2003) The digitization of word of mouth: promise and challenges of online feedback mechanisms. Manag Sci 49:1407-1424

Demil B, Lecocq X (2006) Neither market nor hierarchy nor network: the emergence of bazaar governance. Organ Stud 27: $1447-1466$

Demsetz H (1967) Toward a theory of property rights. Am Econ Rev 57:347-359

Di Fiore A (2018) Why Al will shift decision-making from the C-suite to the frontline. Harvard Bus Rev. https://hbr.org/2018/ 08/why-ai-will-shift-decision-making-from-the-c-suite-to-the-frontline

Dunbar RLM, Starbuck WH (2006) Learning to design organizations and learning from designing them. Organ Sci 17:171-178. https://doi.org/10.1287/orsc.1060.0181

Eccles RG, White HC (1988) Price and authority in inter-profit center transactions. Am J Sociol 94:S17-S51

Felin T, Zenger T (2011) Information aggregation, matching and radical market-hierarchy hybrids: implications for the theory of the firm. Strateg Organ 9:163-173

Fiss PC (2011) Building better causal theories: a fuzzy set approach to typologies in organization research. Acad Manag J 54: 393-420

Fjeldstad ØD, Snow CC, Miles RE, Lettl C (2012) The architecture of collaboration. Strategic Manage J 33:734-750. https://doi. org/10.1002/smj.1968

Frey CB, Osborne MA (2017) The future of employment: how susceptible are jobs to computerisation? Technol Forecast Soc Chang 114:254-280

Galbraith JR (1974) Organization design: an information processing view. Interfaces 4:28-36

Garud R, Jain S, Tuertscher P (2008) Incomplete by design and designing for incompleteness. Organ Stud 29:351-371. https:// doi.org/10.1177/0170840607088018

Garud R, Kurnaraswamy A, Sambamurthy V (2006) Emergent by design: performance and transformation at Infosys Technologies. Organ Sci 17:277-286. https://doi.org/10.1287/orsc.1050.0179

Granovetter M (1985) Economic action and social structure: the problem of embeddedness. Am J Sociol 91:481-510

Griffith TL, Sawyer JE, Neale MA (2003) Virtualness and knowledge in teams: managing the love triangle of organizations, individuals, and information technology. Mis Quart 27:265-287

Gulati R, Puranam P (2009) Renewal through reorganization: the value of inconsistencies between formal and informal organization. Organ Sci 20:422-440

Gulati R, Puranam P, Tushman M (2012) Meta-organization design: rethinking design in interorganizational and community contexts. Strategic Manage J 33:571-586. https://doi.org/10.1002/smj.1975

Gulati R, Singh H (1998) The architecture of cooperation: managing coordination costs and appropriation concerns in strategic alliances. Admin Sci Quart 43:781-814

Handy C (1995) Trust and the virtual organization. Harvard Bus Rev 73:40

Hansen MT (1999) The search-transfer problem: the role of weak ties in sharing knowledge across organization subunits. Admin Sci Quart 44:82-111

Hansen MT (2002) Knowledge networks: explaining effective knowledge sharing in multiunit companies. Organ Sci 13:232-248

Hart O (1995) Firms, contracts, and financial structure. Clarendon Press, Oxford

Hayek FA (1945) The use of knowledge in society. Am Econ Rev 35:519-530 
Heckscher CC, Adler PS (eds) (2006) The firm as a collaborative community: reconstructing trust in the knowledge economy. Oxford University Press, Oxford

Hennart J-F (1993) Explaining the swollen middle: why most transactions are a mix of "market" and "hierarchy". Organ Sci 4:529-547 Hong L, Page SE (2001) Problem solving by heterogeneous agents. J Econ Theory 97:123-163

Hutter K, Hautz J, Füller J, Mueller J, Matzler K (2011) Communitition: the tension between competition and collaboration in community-based design contests. Creat Innov Manag 20:3-21

lansiti M, Lakhani KR (2017) The truth about blockchain. Harvard Bus Rev 95:118-127

Jensen MC, Meckling WH (1976) Theory of the firm: managerial behavior, agency costs and ownership structure. J Financ Econ 3:305-360

Jeppesen LB, Lakhani KR (2010) Marginality and problem-solving effectiveness in broadcast search. Organ Sci 21:1016-1033

Kass A (2016) From static hierarchy to dynamic labor market. Accenture Technology Labs, San Jose

Kolbjørnsrud V (2017) Agency problems and governance mechanisms in collaborative communities. Strateg Organ 15:141173. https://doi.org/10.1177/1476127016653727

Kolbjørnsrud V, Amico R, Thomas RJ (2016) How artificial intelligence will redefine management. Harvard Bus Rev. https://hbr. org/2016/11/how-artificial-intelligence-will-redefine-management

Lakhani KR, von Hippel E (2003) How open source software works: "free" user-to-user assistance. Res Policy 32:923-943. https://doi.org/10.1016/50048-7333(02)00095-1

Lakhani KR et al (2013) Prize-based contests can provide solutions to computational biology problems. Nat Biotechnol 31: 108-111. https://doi.org/10.1038/Nbt.2495

Lawrence PR, Lorsch JW (1967) Differentiation and integration in complex organizations. Admin Sci Quart 12:1-47

Lee GK, Cole RE (2003) From a firm-based to a community-based model of knowledge creation: the case of the Linux kernel development. Organ Sci 14:633-649

Lerner J, Tirole J (2002) Some simple economics of open source. J Ind Econ 50:197-234

Levine P (2006) Collective action, civic engagement, and the knowledge commons. In: Hess C, Ostrom E (eds) understanding knowledge as a commons: from theory to practice. MIT Press, Cambridge, pp 247-275

Makadok R, Coff R (2009) Both market and hierarchy: an incentive-system theory of hybrid governance forms. Acad Manag Rev 34:297-319

March JG (1991) Exploration and exploitation in organizational learning. Organ Sci 2:71-87

March JG, Simon HA (1958) Organizations. Wiley, New York

McEvily B, Perrone V, Zaheer A (2003) Trust as an organizing principle. Organ Sci 14:91-103

McEvily B, Soda G, Tortoriello M (2014) More formally: rediscovering the missing link between formal organization and informal social structure. Acad Manag Ann 8:299-345

Meyer AD, Tsui AS, Hinings CR (1993) Configurational approaches to organizational analysis. Acad Manag J 36:1175-1195

Meyer JW, Rowan B (1977) Institutionalized organizations: formal structure as myth and ceremony. Am J Sociol 83:340-363

Miles RE, Miles G, Snow CC, Blomqvist K, Rocha H (2009) The I-form organization. Calif Manag Rev 51:61-76

Miles RE, Snow CC (1978) Organizational strategy, structure, and process. In: McGraw-Hill series in management. McGraw-Hill, New York

Miles RE, Snow CC, Fjeldstad OD, Miles G, Lettl C (2010) Designing organizations to meet 21st century opportunities and challenges. Organ Dyn 39:93-103. https://doi.org/10.1016/j.orgdyn.2010.01.009

Mintzberg H (1979) The structuring of organizations: a synthesis of the research. Prentice-Hall, Englewood Cliffs

Mintzberg H (1983) Structure in fives: designing effective organizations. Prentice-Hall, Englewood Cliffs

Morgan J, Wang R (2010) Tournaments for ideas. Calif Manag Rev 52:77-97

Mowshowitz A (1994) Virtual organization: a vision of management in the information age. Inf Soc 10:267-288

Nonaka I, Takeuchi H (1995) The knowledge-creating company: how Japanese companies create the dynamics of innovation. Oxford University Press, New York

North DC (1990) Institutions, institutional change, and economic performance. The political economy of institutions and decisions. Cambridge University Press, Cambridge

NTL (2018) NASA Tournament Lab. https://www.nasa.gov/coeci/ntl. Accessed February 212018

O'Keefe B, Lovas B (2002) Oticon A/S. London: London Business School

O'Mahony S, Ferraro F (2007) The emergence of governance in an open source community. Acad Manag J 50:1079-1106

Ostrom E (1990) Governing the commons: the evolution of institutions for collective action. In: The political economy of institutions and decisions. Cambridge University Press, New York

Ostrom E (2000) Collective action and the evolution of social norms. J Econ Perspect 14:137-158

Ostrom E, Hess C (2006) A framework for analyzing the knowledge commons. In: Hess C, Ostrom E (eds) Understanding Knowledge as a Commons: From Theory to Practice. MIT Press, Cambridge, pp 41-81.

Ouchi WG (1980) Markets, bureaucracies, and clans. Admin Sci Quart 25:129-141

Pettersen L (2017) Rating mechanisms among participants in sharing economy platforms. First Monday:22

Poetz MK, Schreier M (2012) The value of crowdsourcing: can users really compete with professionals in generating new product ideas? J Prod Innov Manag 29:245-256

Porter ME (1990) The competitive advantage of nations. Free Press, New York

Powell WW (1990) Neither market nor hierarchy: network forms of organization. Res Organ Behav 12:295-336

Powell WW, Koput KW, Smith-Doerr L (1996) Interorganizational collaboration and the locus of innovation: networks of learning in biotechnology. Admin Sci Quart 41:116-145

Powell WW, White DR, Koput KW, Owen-Smith J (2005) Network dynamics and field evolution: the growth of interorganizational collaboration in the life sciences. Am J Sociol 110:1132-1205

Puranam P, Alexy O, Reitzig M (2014) What's "new" about new forms of organizing? Acad Manag Rev 39:162-180. https://doi. org/10.5465/amr.2011.0436

Puranam P. Vanneste BS (2009) Trust and governance: untangling a tangled web. Acad Manag Rev 34:11-31

Rochet JC, Tirole J (2003) Platform competition in two-sided markets. J Eur Econ Assoc 1:990-1029

Schreyögg G, Sydow J (2010) Crossroads-organizing for fluidity? dilemmas of new organizational forms. Organ Sci 21:1251-1262

Seibel W (2015) Studying hybrids: sectors and mechanisms. Organ Stud 36:697-712 
Seidel M-DL, Stewart KJ (2011) An initial description of the C-form. Res Sociol Organ 33:37-72

Shah SK (2006) Motivation, governance, and the viability of hybrid forms in open source software development. Manag Sci 52:1000-1014

Shane SA (1996) Hybrid organizational arrangements and their implications for firm growth and survival: a study of new franchisors. Acad Manag J 39:216-234

Shelanski HA, Klein PG (1995) Empirical research in transaction cost economics: a review and assessment. J Law Econ Organ 11:335-361

Short JC, Payne GT, Ketchen DJ Jr (2008) Research on organizational configurations: past accomplishments and future challenges. J Manage 34:1053-1079

Simon HA (1962) The architecture of complexity. Proc Am Philos Soc 106:467-482

Simon HA (1973) Applying information technology to organization design. Public Adm Rev 33:268-278

Simon HA (1991) Organizations and markets. J Econ Perspect 5:25-44

Snow CC, Fjeldstad ØD, Lettl C, Miles RE (2011) Organizing continuous product development and commercialization: the collaborative community of firms model. J Prod Innov Manag 28:3-16

Stiglitz JE (1989) Markets, market failures, and development. Am Econ Rev 79:197-203

Stiglitz JE (1990) Peer monitoring and credit markets. World Bank Econ Rev 4:351-366

Sugumaran G (2012) Open Source Drug Discovery: redefining IPR through open source innovations. Curr Sci 102:1637-1639

Thompson JD (1967) Organizations in action: social science bases of administrative theory. McGraw-Hill, New York

TopCoder.com (2018) TopCoder. https://www.topcoder.com/. Accessed February 212018

Trouiller P, Olliaro P, Torreele E, Orbinski J, Laing R, Ford N (2002) Drug development for neglected diseases: a deficient market and a public-health policy failure. Lancet 359:2188-2194

Uzzi B (1997) Social structure and competition in interfirm networks: the paradox of embeddedness. Admin Sci Quart 42:35-67

Van Maanen J, Barley SR (1984) Occupational communities: culture and control in organizations. Res Organ Behav 6:287-365

von Hippel E, von Krogh G (2003) Open source software and the "private-collective" innovation model: issues for organization science. Organ Sci 14:209-223

Wenger E (1998) Communities of practice: learning, meaning, and identity. Learning in doing. Cambridge University Press, New York WHO (2017) Global tuberculosis report. World Health Organization, Geneva, p 2017

Williamson OE (1975) Markets and hierarchies, analysis and antitrust implications: a study in the economics of internal organization. Free Press, New York

Williamson OE (1979) Transaction-cost economics: governance of contractual relations. J Law Econ 22:233-261

Williamson OE (1991) Comparative economic organization: the analysis of discrete structural alternatives. Admin Sci Quart 36:269-296

Williamson OE (1996) The mechanisms of governance. Oxford University Press, Oxford

Wolfers J, Zitzewitz E (2004) Prediction markets. J Econ Perspect 18:107-126

Zammuto RF, Griffith TL, Majchrzak A, Dougherty DJ, Faraj S (2007) Information technology and the changing fabric of organization. Organ Sci 18:749-762

Zenger TR, Hesterly WS (1997) The disaggregation of corporations: selective intervention, high-powered incentives, and molecular units. Organ Sci 8:209-222

Zervas G, Proserpio D, Byers JW (2017) The rise of the sharing economy: estimating the impact of Airbnb on the hotel industry. J Marketing Res 54:687-705

Zheng H, Li D, Hou W (2011) Task design, motivation, and participation in crowdsourcing contests. Int J Electron Commerce 15:57-88

\section{Submit your manuscript to a SpringerOpen ${ }^{0}$ journal and benefit from:}

- Convenient online submission

Rigorous peer review

- Open access: articles freely available online

High visibility within the field

- Retaining the copyright to your article

Submit your next manuscript at $>$ springeropen.com 